Research Paper

\title{
Could smart growth lower the operational energy of water supply? A scenario analysis in Tampa, Florida, USA
}

\author{
Mark V. Santana $^{1}$, Qiong Zhang, Mahmood H. Nachabe, Xiongfei Xie, James R. Mihelcic \\ Civil \& Environmental Engineering, University of South Florida, 4202 E. Fowler Ave., ENB 118, Tampa, FL, 33620, United States
}

\section{A R T I C L E I N F O}

\section{Keywords:}

Urban planning

Water supply

Water distribution

Life cycle assessment

Emboddied energy

Climate

\begin{abstract}
A B S T R A C T
Cities are coming under increasing pressure to minimize energy use and greenhouse gas emissions. Consequently, drinking water utilities must improve the efficiency of their management systems while guaranteeing a clean effluent that satisfies drinking water standards. One possible solution is via smart growth, an urban development paradigm with the goal of reducing the environmental impact of urbanization. Therefore, this study aims to determine the effect of smart growth on the operational energy of drinking water distribution. Projected water use in Tampa's drinking water service area was estimated based on several urban growth projections. Then, each scenario's associated projected water consumption is integrated in an EPANET simulation of Tampa's water distribution system for the subsequent estimation of the operational energies of drinking water distribution. Results show that smart growth has no exclusive influence on the operational energy of water supply. However, location of added demand relative to the location of the water treatment plant has more of an influence on the operational energy. Also, smart growth in the City of Tampa Water Service Area is responsible for a decrease in per-capita residential water and energy use of about $6-10 \%$ and $0.5-6.2 \%$ respectively. In conclusion, smart growth in areas near the water treatment facility may minimize water-related energy use.
\end{abstract}

\section{Introduction}

By 2050, the world's population is expected to reach 9.6 billion people with $60 \%$ living in cities (United Nations, 2010). This highly urbanized and increasingly affluent population will require more energy, land conversion, resource use, and agricultural development, all which may result in elevated greenhouse gas (GHG) emissions (Yeh \& Huang, 2012). Another important resource required for community well-being is water, which, in many cities, is provided via centralized water treatment and supply schemes. The energy use associated with water provision over its life cycle can be quantified with embodied energy, defined as the direct (i.e., on-site) and indirect (i.e., consumed offsite) energy needed to produce a unit volume of treated water (Amores, Meneses, Pasqualino, Anton, \& Castells, 2013; Del Borghi, Strazza, Gallo, Messineo, \& Naso, 2013; Mo, Zhang, Mihelcic, \& Hokanson, 2011; Santana, Zhang, \& Mihelcic, 2014). Because the water sector is responsible for up to one-third of total municipal energy use (Yonkin, Clubbine, \& O'Connor, 2008), cities and water utilities must confront the challenge of achieving energy efficiency in addition to water availability and quality.

Water treatment and supply systems consist of three main energyconsuming components: collection, treatment, and distribution (storage is considered a part of distribution). Past studies have estimated the total energy use of water treatment and supply systems at the regional (Del Borghi et al., 2013), metropolitan (Lundie, Peters, \& Beavis, 2004), and municipal scales (Amores et al., 2013; Mo et al., 2011). Estimated embodied energies from these studies ranged from $5.2-54.1 \mathrm{MJ} / \mathrm{m}^{3}$ of water produced, with factors including the water source, treatment process, and piping distance responsible for this wide range. For instance, desalination consumes about 8-10 times more energy per unit of water produced than conventional treatment systems included in the same studies, making treatment (desalination process) responsible for about $65-81 \%$ of the total energy use in water management systems where it is included (Amores et al., 2013; Cornejo, Santana, Hokanson, Mihelcic, \& Zhang, 2014; Del Borghi et al., 2013). Conversely, when water systems rely on conventional systems, treatment is only responsible for $17-30 \%$ of the total energy use, making distribution the greatest contributor (Amores et al., 2013; Lundie et al., 2004).

\footnotetext{
* Corresponding author.

E-mail addresses: mvsantana@mail.usf.edu (M.V. Santana), qiongzhang@usf.edu (Q. Zhang), nachabe@usf.edu (M.H. Nachabe), xxie@co.pinellas.fl.us (X. Xie), jm41@usf.edu (J.R. Mihelcic).

${ }^{1}$ Present address: Institut Català de la Recerca de l'Aigua, (Catalan Water Research Institute), Edifici H2O, Parc Scientific i Technologic de la University de Girona, Emili Grahit, 101, E17003, Girona, Spain.
} 
Table 1

The ten principles of Smart Growth (Smart Growth Network, 2006).

- Mix land uses

- Take advantage of compact building design

- Create a range of housing opportunities and choices

- Create walkable neighborhoods

- Foster distinctive, attractive communities with a strong sense of place

- Preserve open space, farmland, natural beauty, and critical environmental areas

- Strengthen and direct development towards existing communities

- Provide a variety of transportation choices

- Make development decisions predictable, fair, and cost effective

- Encourage community and stakeholder collaboration in development decisions

In the United States, since centralized potable water systems tend to rely on conventional treatment of surface water and groundwater, distribution is often the largest contributor to overall embodied energy.

Distribution systems usually follow transportation networks and are influenced by urban form. Filion (2008) modeled the distribution systems of three theoretical cities with distinct urban forms: gridiron, radial, and satellite. For each "city", three distinct population distributions were applied: "uniform", "monocentric", and "polycentric". A life cycle energy assessment (LCEA) was conducted for each scenario. Cities that followed a radial form (similar to older European cities) as well as a higher population density in and near the center of each city resulted in lower life cycle energy values.

Smart growth is a development paradigm commonly employed in North America in which urban growth has a lower environmental impact as well as a positive social impact. In other parts of the world, the terms compact city or urban intensification describe similar principles of sustainable city planning. It is guided by the ten principles listed in Table 1 (Smart Growth Network, 2006). Smart growth generally encourages a more compact urban form, which is amenable to pedestrians and various alternative forms of transit (i.e. buses, light rail). UN-Habitat (2013) and UNEP (2011) see similar principles of compact urban planning, walkability, stakeholder engagement, and access to green space as key features of a sustainable city and the new green economy. Past research has shown that smart growth and similar forms of urban development can result in decreased environmental impact, especially via transportation through reductions in air pollution emissions due to less vehicular traffic. For instance, Behan, Maoh, and Kanaroglou (2008) used an integrated transportation simulation model to simulate current and smart growth trends and found that smart growth was projected to use about $25 \%$ less fuel and emit $30 \%$ less carbon monoxide (CO) than the "base case." Other studies have modeled a reduction in emissions of the greenhouse gas carbon dioxide $\left(\mathrm{CO}_{2}\right)$ when smart growth is the preferred urban transportation scenario (Hankey \& Marshall, 2010; Lee \& Lee, 2014). The implementation of transit-oriented development (TOD) was studied by carrying out a life cycle assessment (LCA) of the areas surrounding two bus lines in Los Angeles and observed a relative decrease in greenhouse gas (GHG) emissions, smog formation and associated particulate matter, compared to the "business-as-usual" scenario (Nahlik \& Chester, 2014).

Though not specifically mentioned in its ten principles, smart growth does have an impact on water. For example, watersheds with at least $10 \%$ impervious area have been associated with degraded water quality and increased sprawl and are expected to create $43 \%$ more stormwater runoff (Pelley, 2004). However, only a few studies have looked specifically at the effects of smart growth on water supply management, especially focusing on how it impacts residential water use (Guhathakurta \& Gober, 2007; Runfola et al., 2013). There has been no study investigating how the urbanization paradigm of smart growth may influence the energy performance of an existing water distribution system. Because water management can be responsible for a significant amount of municipal energy use, the impact that the type of urban development has on energy use in water management should be important, especially as it relates to the economic cost of providing water, and consequently, associated greenhouse gas (GHG) emissions. Therefore, this study examines the impacts of smart growth on the energy performance of water management by comparing the operational energy of water distribution in four future development scenarios in rapidly growing city, three of which incorporate principles of smart growth.

The research is guided by the following hypothesis: urban planning that incorporates principles of smart growth will reduce the operational energy of a piped water distribution system. One basis for this hypothesis is that water consumption is expected to be reduced for planning scenarios that result in a more compact city. The second is that because urban intensification is expected to reduce the energy associated with transporting people, it should similarly result in less energy required to move water. Tampa (Florida) provides the case study to test this hypothesis and is a representative example of a large, and rapidly growing coastal urban area with multiple decisions for its future development, similar to many other growing coastal cities of the world, which comprise three-quarters of all cities in the world (UNEP). In addition, Tampa is an example of an urban area with a development paradigm dominated by urban sprawl (Hillsborough County Metropolitan Planning Organization, 2009). The methodology and conclusions reached in this study are thus relevant to not only coastal, but other urban centers in the world, as many cities face the same challenges of providing water to a growing urban population, while realizing the need to better plan their communities, limit energy use, and curb emission of greenhouse gases.

\section{Methods}

\subsection{Site description}

Tampa is one of the main cities of the Tampa St. PetersburgClearwater Metropolitan Area. The city's current population has grown 10.7\%, since 2000 (Florida Center for Community Design and Research, 2015). The city is relatively sprawled with a population density of about 1862 people per square mile. The city lies within the City of Tampa Water Service Area (Tampa WSA), which is responsible for providing potable water to Tampa and a small number of outlying unincorporated communities (Fig. 1). About 68 million gallons per day (MGD) $\left(257,000 \mathrm{~m}^{3} /\right.$ day) of water is extracted from the Hillsborough River Reservoir, treated via the David L. Tippin Water Treatment Facility (Tippin WTF), and pumped through a 134,000-pipe distribution system to provide potable water to approximately 588,000 customers.

\subsection{The one Bay urban development initiative}

One Bay is a consortium of public and private entities in the Tampa Bay area with the objective of encouraging development that incorporates the principles of sustainability. In 2007, over three hundred leaders were invited by One Bay to participate in a workshop called "Reality Check" to determine priority areas of future development in the Tampa-St. Petersburg-Clearwater (TSC) metropolitan area. In 2008, One Bay created four future growth scenarios to simulate the effects of different development paradigms on land use, transportation, water use, employment, and housing (Fig. 2). "Business as Usual" (BAU) is a continuation of current growth patterns. The "Preferred" scenario is the resultant plan of the "Reality Check" workshops. The "Compact" scenario projects more compact urban design via a clear preference for multi-family housing development concentrated in existing urban areas. Meanwhile, the "Green" scenario avoids construction in or near protected or sensitive areas. The latter three scenarios will be referred to as smart growth scenarios, as they are guided by the principles of compact design and "development towards existing communities", resulting in an increased addition of multi-family households and a focus on residential and commercial development within existing urban 


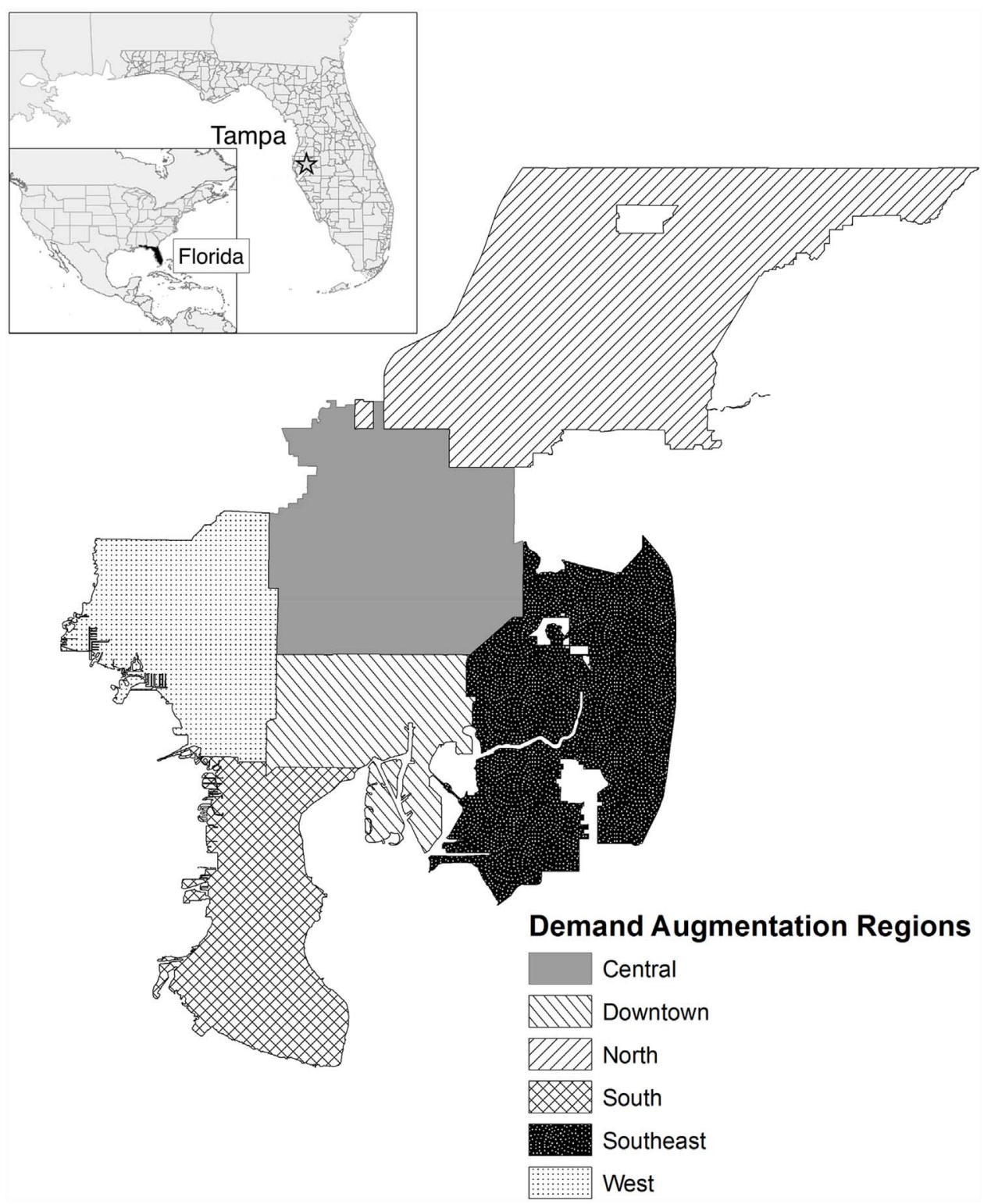

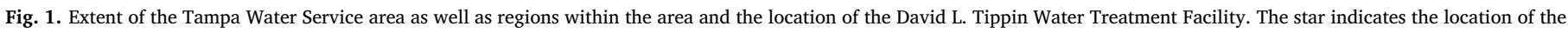
water treatment facility in Tampa, Florida (USA).

areas.

\subsection{Data}

\subsubsection{Future development scenarios}

The Tampa Bay Regional Planning Council (TBRPC) provided several GIS shapefiles that illustrate the future growth projections of the four future development scenarios outlined in the One Bay Initiative. The files were represented via a dot matrix with each "dot" representing a 39-acre area of land, containing the number of households and jobs that were projected to be added to the existing amount by about 2050. Descriptions of each development scenario are presented in Table 2.

\subsubsection{Smart location database}

Existing employment and household data were extracted from the Smart Location Database, which is maintained by the Environmental Protection Agency (EPA) and was originally created to determine the "location efficiency" with respect to urban planning and transportation of communities throughout the United States (Ramsey \& Bell, 2014).
Information is aggregated at the census block group level and consists of data relating to density, mix of land uses, road density, and location of the population with respect to jobs and transportation. Housing unit and employment data were based on 2010 Census values.

\subsubsection{Water use}

Current water use data was provided by Tampa Bay Water (Clearwater, FL) via a database called GOVNET. This GIS database spatially organizes monthly water consumption of all accounts within the jurisdiction of Tampa Bay Water into a parcel-level shapefile. For the purposes of this study, the shapefile was clipped to the data within the boundaries of the Tampa WSA. The monthly water consumption values for the year 2011 were summed for each account since 2011 was the most recent year that data was collected for GOVNET.

\subsubsection{Water distribution}

A GIS shapefile of the Tampa WSA's distribution system was provided by the City of Tampa Water Department. The shapefile contains the data for the approximately 134,000 pipes that make up the water distribution system. This data includes physical character- 

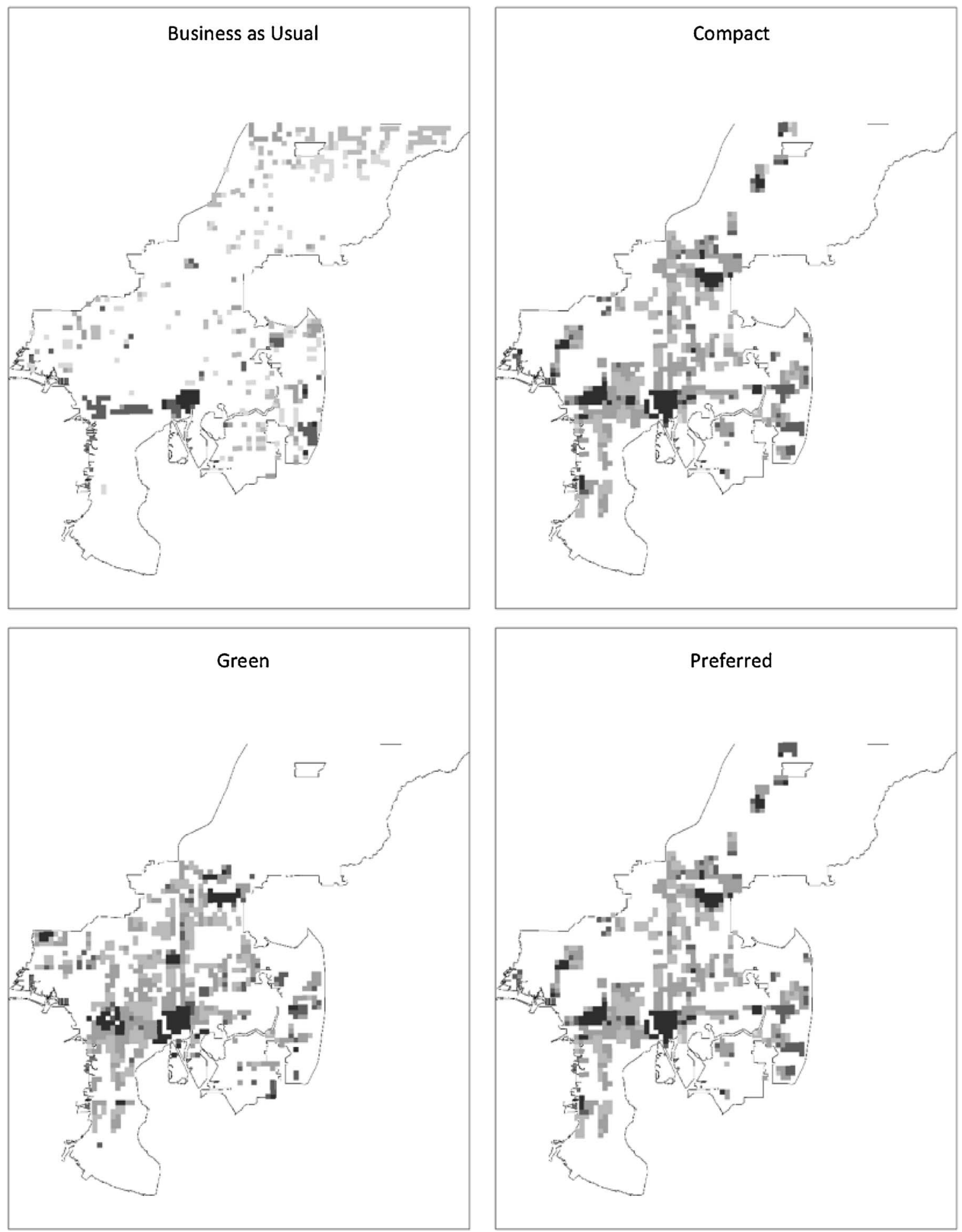

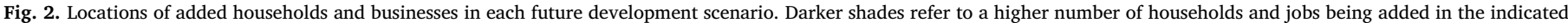
area.

istics such as pipe diameter, length, material, and the year of installation. Pipes in the system range from 0.5 to 54 inches (13-1372 mm) in diameter and are composed of $85 \%$ ductile iron pipes, $9 \%$ cast iron, $3 \%$ galvanized iron, $2 \% \mathrm{HDPE}$, and $1 \%$ PVC by length. In addition the Water Department also provided the locations of the three repump stations (and corresponding tanks) and one booster pump station.

\subsection{Data processing}

\subsubsection{Creation of the base hydraulic model}

The skelebrator tool in WaterGems (Exton, PA) was used to simplify the Tampa WSA distribution system shapefile from a network of 134,000 pipes to just over 800 pipes. The tool combines pipes, placed in series or run parallel to each other, to one equivalent pipe and also consolidates branched pipes. All pipes in the system were assumed to be new ductile iron. As a result, this study's findings were not affected by 
Table 2

Explanation of the different development scenarios within the City of Tampa Water Service Area modeled by One Bay Development Initiative.

\begin{tabular}{|c|c|c|c|c|}
\hline Name & $\begin{array}{l}\text { Number of New } \\
\text { Households }\end{array}$ & $\begin{array}{l}\text { Number of New } \\
\text { Jobs }\end{array}$ & 2050 Population & Description \\
\hline $\begin{array}{l}\text { Business as Usual } \\
\text { (BAU) }\end{array}$ & 59,577 & 132,717 & 742,900 & $\begin{array}{l}\text { Growth projections based on current trends; Predominance of new single family home } \\
\text { construction outside of urban areas }\end{array}$ \\
\hline Preferred & 208,881 & 353,655 & $1,131,091$ & $\begin{array}{l}\text { Growth projections based on the consensus reached during the "Reality Check" workshops. } \\
\text { Approved by municipal leaders, planners and other stakeholders. Increased development in } \\
\text { existing urban areas. Increase in new multifamily home construction }\end{array}$ \\
\hline Compact & 208,410 & 348,288 & $1,129,866$ & $\begin{array}{l}\text { The incorporation of compact design; Focus mainly on mixed-use multifamily construction; } \\
\text { Development in existing urban areas }\end{array}$ \\
\hline Green & 169,824 & 287,538 & $1,029,542$ & $\begin{array}{l}\text { Development is prohibited on or near protected or sensitive areas; Increased building of } \\
\text { multi-family housing }\end{array}$ \\
\hline
\end{tabular}

pipe condition. Repump stations were excluded as they are mainly used for fire flows. However, the booster station was included as it is used to aid in the provision of water to the northern section of the Tampa WSA. Next, the 2011 water consumption at each junction was incorporated into the hydraulic model in ArcGIS by aggregating the water consumption of the nearest parcels to each water distribution network junction via a proximity geoprocessing function. The resultant shapefiles with the junctions, pipes, pumps, and reservoir were then incorporated into an EPANET (Cincinnati, OH) file using the QGIS software plugin GHydraulics (Uelzen, Germany).

\subsubsection{Development scenario creation}

According to Xiang and Clarke (2003), good scenarios that inform the decision making process should have 1) plausible and surprising futures, 2) informational vividness, and 3) ergonomic design. The scenarios in this study were created by a consortium of municipal representatives and based on a workshop attended by a diverse group of community leaders and stakeholders. The plausibility and surprise of scenario creation was thus based on participants who not only had familiarity with or lived in the region, but were also required to incorporate features of sustainability and smart growth, both which are new alternatives to the area's more traditional development pattern of urban sprawl. The informational vividness of creating scenarios was addressed by placing future commercial and residential development in temporal proximity and easy to imagine areas representing 39-acre parcels. Finally, the ergonomic design of the scenario development was addressed because the study compared four distinct future development scenarios, each with a different guiding theme of development.

The future development scenarios provided by TBRPC cover the entire Tampa-St. Petersburg-Clearwater Metropolitan area including Hillsborough, Pinellas, Hernando, and Polk Counties. Each scenario projects a future population of about 7 million inhabitants in the entire Tampa Bay region from the current 2.8 million inhabitants in 2011 (U.S. Census Bureau, 2013). Therefore, each scenario GIS shapefile was clipped to fit the boundaries of the Tampa WSA. Each new household was estimated to contain 2.6 people based on the assumptions made by One Bay. The resultant scenarios project different future populations to be served by the city of Tampa Water Department (see Table 2), given the assumptions that the boundaries of the Tampa WSA do not change and that more growth within the Tampa WSA translates into less population growth outside of the WSA.

While the Preferred and Compact development scenarios add a similar amount of households to the Tampa WSA, BAU only adds 59,577 households, which is a little over a quarter of the amount added in the Preferred and Compact scenarios and less than a third of the households added in the Green scenario. In addition to added households, the growth scenarios also have different future compositions of housing types (Fig. 3). For example, in the BAU scenario, $60 \%$ of housing is single-family detached homes. In the other scenarios, multifamily homes and townhomes comprise the majority of all housing, reflecting a shift towards compact design.

\subsubsection{Water consumption projection}

Future water consumption for the various development scenarios was estimated as the sum of the existing 2011 water consumption and the added water consumption due to new households and employment. An observation of average single-family home consumption values (in gallons per unit per day, GPUD) from 2002 to 2008 showed values stabilizing around an average of 254 GPUD (Hazen and Sawyer, 2013). Therefore, for the purposes of this study, the water consumption in existing households was assumed to not change from 2011 values, and any major changes would be from the addition of new households.

New household and employment water consumption values were separated into four categories: 1) single family household, 2) multifamily household, 3) townhomes, and 4) employment. Household water consumption data was obtained from the 2013 Tampa Bay Water Demand Management Plan (Hazen and Sawyer, 2013). This data was based on households within the boundaries of the City of Tampa. Multifamily household water consumption was estimated as the weighted average of buildings with less than 10 units, 10 or more units, and condominiums. The weights were determined by the composition of multifamily housing built from 2008 to 2012 (U.S. Census Bureau, 2013). Per-employee average daily water consumption was based on the estimations made by Nelson (2004). On average, single-family homes consume about 254 gallons per unit per day (GPUD) (961 liters per unit per day, LPUD), which is almost double the average consumption value of multi-family households and townhouses (137 and 138 GPUD or 518 and 522 LPUD, respectively). This higher unitary consumption value for single family homes may be in part due to outdoor water uses (irrigation, pools), which in the case of the TampaSt. Petersburg-Clearwater Metropolitan area is on average $25 \%$ of total water use in the average single family house (Hazen and Sawyer, 2013). For single-family homes, Tampa is slightly below the national average of about 300 GPUD (Environmental Protection Agency, 2016). Compared to other cities that are similar in layout (i.e. Santa Fe, Tuscon, Jacksonville, Phoenix, La Vegas and San Jose), it is one of the larger values in the range of 133 (Jacksonville) - 374 (San Jose) (Walton, 2016).

For the data points containing the number of added households and jobs in the shapefile for each scenario, the total new household water consumption was estimated as:

$W_{R}=\left(P_{S} C_{S} H\right)+\left(P_{M} C_{M} H\right)+\left(P_{T} C_{T} H\right)+\left(E C_{E}\right)$

In Equation (1), $\mathrm{W}_{\mathrm{R}}$ is the new household water consumption (in gallons per minute, GPM). $\mathrm{P}_{\mathrm{S}}, \mathrm{P}_{\mathrm{M}}$, and $\mathrm{P}_{\mathrm{T}}$ are the percentages of added single-family households (SFH), multi-family households (MFH), and townhome households $(\mathrm{TH})$, respectively. $\mathrm{C}_{\mathrm{S}}, \mathrm{C}_{\mathrm{M}}$, and $\mathrm{C}_{\mathrm{T}}$ are the unitary consumption values for each SFH, MFH, and TH (GPM), respectively. $\mathrm{H}$ is the total number of households added over the next 40 years. The employee water consumption ( $\left.\mathrm{C}_{\mathrm{E}}, \mathrm{GPM}\right)$ was based on the values from Nelson (2004) and assumed the same for all employment. It was multiplied by the amount of employment (E) for each data point. Once calculated, these points were summed at the nearest junction in the simplified hydraulic model. The new water consumption was then 


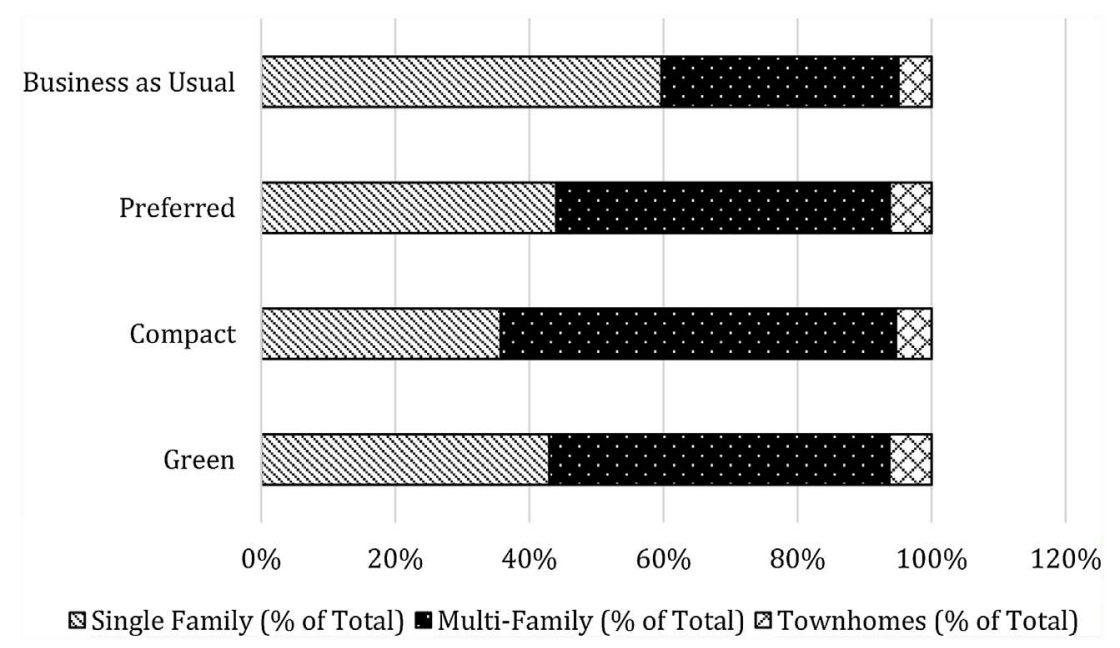

Fig. 3. Household type composition for each future One Bay development scenario within the Tampa Water Service Area.

added to the existing water consumption at the same junction to create a hydraulic model for each scenario. The hydraulic model was exported to EPANET (Environmental Protection Agency, 2008), a water distribution modeling software, and then run (assuming constant demand for simplification purposes). The pumps were set at the lowest power to achieve a minimum pressure of about $50 \mathrm{psi}(345 \mathrm{kPa})$ at each junction. For this study, it is assumed that the Hillsborough River Reservoir as well as the existing water infrastructure (pumps and pipes) will be able to satisfy the demand for all future scenarios.

\subsection{Operational energy calculation}

Past embodied energy analyses of water supply systems show that the operation phase (pumping of water through the water distribution system) has the highest contribution to total embodied energy (69-96\% of total embodied energy) (Fillion et al., 2008; Mo et al., 2011; Stokes \& Horvath, 2011). Therefore this study will focus on the operational energy, which is defined as the energy associated with supplying a unit volume of water to users. In this study, this principally refers to the energy used to pump water throughout the distribution system per unit volume of water used. EPANET was used to model each future water use scenario. After each simulation, the energy use per unit volume water consumed was obtained from EPANET's built-in energy analysis option. However, this value only accounted for the electricity used for pumping and not the energy used to produce the electricity. Therefore, energy use per volume of water was multiplied by an energy density of $3.48 \mathrm{MJ}$ consumed/MJ produced, which is based on a cumulative energy demand analysis done in SimaPro (Amersfoort, The Netherlands) of the average mix for the United States. This same procedure was used previously to calculate the embodied energy contribution for water treatment in the study area (Santana et al., 2014). Annual per capita water use and water supply energy use were also estimated for each scenario. Per-capita water use was estimated by normalizing the total water demand in each scenario by the total future population within the Tampa WSA. Per-capita water supply energy use was estimated by multiplying the per-capita water use by the operational energy. This metric was also used by Filion (2008) to compare the water supply energy usage of different urban forms.

\subsection{Demand augmentation analysis}

To further determine the degree to which the operational energy of water supply is influenced by the location of extra demands, a demand augmentation analysis was conducted in which a total demand of 20 million $\mathrm{m}^{3}$ of water per year was added over different regions of the Tampa WSA in addition to current demand. These regions were illustrated in Fig. 1. The operational energy was calculated using the same methodology as that of the One Bay scenarios.

\section{Results}

The operational energy of water distribution in the future development scenarios was $3.32 \mathrm{MJ} / \mathrm{m}^{3}$ for the baseline BAU scenario, $3.47 \mathrm{MJ} / \mathrm{m}^{3}$ for the Preferred scenario, $3.45 \mathrm{MJ} / \mathrm{m}^{3}$ for the Compact scenario, and $3.42 \mathrm{MJ} / \mathrm{m}^{3}$ for the Green scenario. Compared to 2011 operational energy (Base, $3.30 \mathrm{MJ} / \mathrm{m}^{3}$ ), all future development scenario operational energies are projected to rise. This is partially because routing a larger volume of water through the same infrastructure will cause an increase in operational energy. Nevertheless, the differences between the future development scenario operational energy values are minimal, as the largest difference (between the BAU and Preferred scenarios) is approximately $4 \%$. In fact, smart growth has an opposite impact on the operational energy with the Preferred development scenario having the highest operational energy, followed by the Compact, Green, and BAU scenarios, respectively.

\subsection{Spatial distribution of operational energy}

The results of the demand augmentation analysis hint that location of extra demand may play a part in explaining the small differences between the future development scenarios. According to Table 3, increased demand farther away from the location of the water treatment plant raises the operational energy of water supply in the Tampa WSA up to $11 \%$. The largest associated operational energy value is associated with additional demand in West Tampa $\left(3.69 \mathrm{MJ} / \mathrm{m}^{3}\right)$, which is followed by demand increases in South and North Tampa, while Central, Downtown, and Southeast Tampa have (5-10\%) lower operational energy values. The higher operational energy values are mostly due to the extra energy needed to transport water a longer distance while ensuring a minimum pressure of about 50 psi ( $345 \mathrm{kPa})$.

The percentage of added demand relative to the base 2011 demand

Table 3

Operational energy values of different water demand augmentation scenarios.

\begin{tabular}{ll}
\hline Region of Tampa & Operational Energy $\left(\mathrm{MJ} / \mathrm{m}^{3}\right)$ \\
\hline Central & 3.32 \\
Downtown & 3.37 \\
North & 3.49 \\
South & 3.51 \\
Southeast & 3.33 \\
West & 3.69 \\
\hline
\end{tabular}




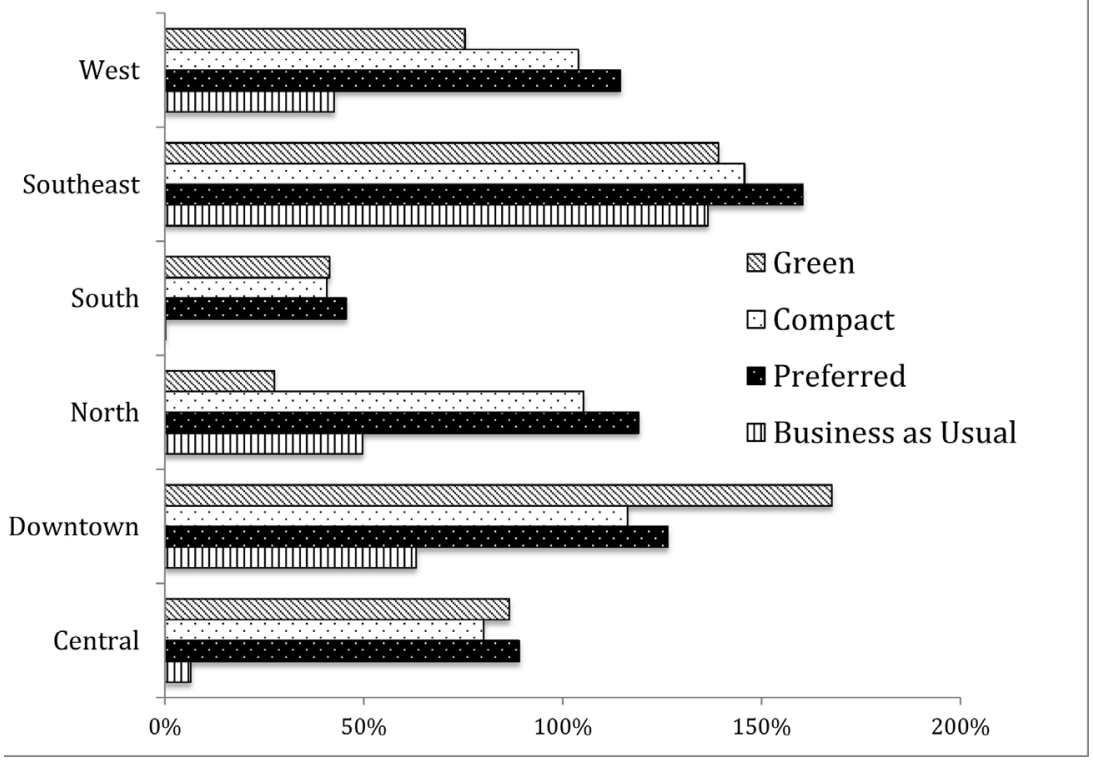

Fig. 4. City of Tampa Water Service Area water demand percentage increases in each region by future development scenario relative to 2011 consumption.

for each future development scenario in each augmentation area is presented in Fig. 4. The highest proportional increases in demand are in the Southeastern and Downtown regions. The Southeastern section of the Tampa WSA is currently suburban in character, yet still has a fair amount of green space. Therefore, this is also prime land for future development, evidenced by the high demand increase ranging from 136 to $168 \%$ of the 2011 demand. Currently, the addition of more jobs and residences downtown also results in demand increases for each scenario that range from 63 to $168 \%$ of the 2011 demand. The lowest demand increases are associated with South Tampa (0-45\%). This area contains dense, historic neighborhoods that are generally built-out, which can explain the relatively lower amount of growth in demand in the area (Florida Center for Community Design and Research, 2015).

When comparing scenarios, demand increases in the smart growth scenarios ("Preferred", "Compact", and "Green") tend to be higher than those of the BAU scenario. This can be seen in the West, Downtown, Central, and South regions of the Tampa WSA (see Fig. 1). The main reason for this could be the quantity of households and jobs that are added to the Tampa WSA in the BAU scenario, which are about a quarter to one-third of those households added to the smart growth scenarios (BAU scenario development is mostly outside of the Tampa WSA). Based on the results from the demand augmentation scenarios, the differences in the South and West regions of the WSA may be responsible for the relatively higher operational energies in the smart growth scenarios compared to the BAU scenario. In the western region, the BAU scenario increases the demand by about $42 \%$, which is substantially lower than the percentage increases associated with the smart growth scenarios (75-114\%). In the southern section of the Tampa WSA, the BAU scenario adds almost no new housing or employment due to the relative lack of space for single-family homes. Nevertheless, the smart growth scenarios project demand increases of $41-45 \%$, due to the addition of predominantly multi-family housing. The highest demand increases in the BAU scenario occur in Southeast Tampa with an expected demand increase of about $136 \%$ most likely due to the availability of land for development of single-family households. However, this increase is still smaller than the $139-160 \%$ increases associated with the smart growth scenarios. Also, based on the demand augmentation scenario, additional demand in the Southeast Tampa WSA has a negligible impact on the operational energy.

Between smart growth scenarios, operational energy differences may also be explained by the comparison of additional demands. For example, the Preferred scenario has consistently higher demand increases than the Compact scenario. This is mainly due to housing composition as both scenarios add a similar number of households and jobs in the same areas. In the preferred scenario, $50 \%$ of housing was classified as multi-family compared to the $59 \%$ of the Compact scenario. In the city of Tampa, average multifamily housing water use is about $50 \%$ of that of single-family homes (Hazen and Sawyer 2013). The comparison with the Green scenario is more complex as the scenario projects the highest demand increase downtown (168\%) while adding the least demand in the northern section of the Tampa WSA (27\%). The lower operational energy of the Green scenario compared to the Preferred and Compact scenarios may be attributed to the lower additional demands in the northern and western regions of the Tampa WSA, as overall operational energies in these regions are more sensitive to additional demand.

\subsection{Per-capita water distribution operational energy}

Fig. 5 compares the per-capita energy and water usages associated with water supply in the Tampa WSA. The per-capita operational energy is defined as the product of the scenario's operational energy and the per-capita water use. The Preferred scenario has the highest per-capita energy use (358 $\mathrm{MJ} /$ person/year) and the highest water usage $\left(103 \mathrm{~m}^{3} /\right.$ person/year). Conversely, the Compact scenario has the lowest per-capita energy and water usage (339 MJ/person/year, $98 \mathrm{~m}^{3} /$ person/year). The differences in both energy and water usage are minimal as the largest difference between values (Preferred vs. Compact) is about $5 \%$. However, this comparison also shows how both energy density and water consumption influence per-capita water supply operational energy use. For instance, the difference between the Preferred and Compact scenarios is mainly due to household water consumption. About $36 \%$ of households in the Compact scenario are single-family homes, compared to $44 \%$ in the Preferred scenario. In Tampa, the larger percentage of single-family homes translates into a higher per-capita water use, and subsequently, per capita water supply energy use in the Preferred scenario.

Another notable result is that the BAU scenario's relatively high percapita water use $\left(103 \mathrm{~m}^{3}\right.$ /person/year) is slightly below that of the Preferred scenario. This result is unexpected as about $60 \%$ of households in the BAU scenario are classified as single-family, which on average consume about twice as much water as multifamily homes and townhouses, while the percentage of single-family households is $44 \%$ for the Preferred scenario. This discrepancy is attributed to the added 


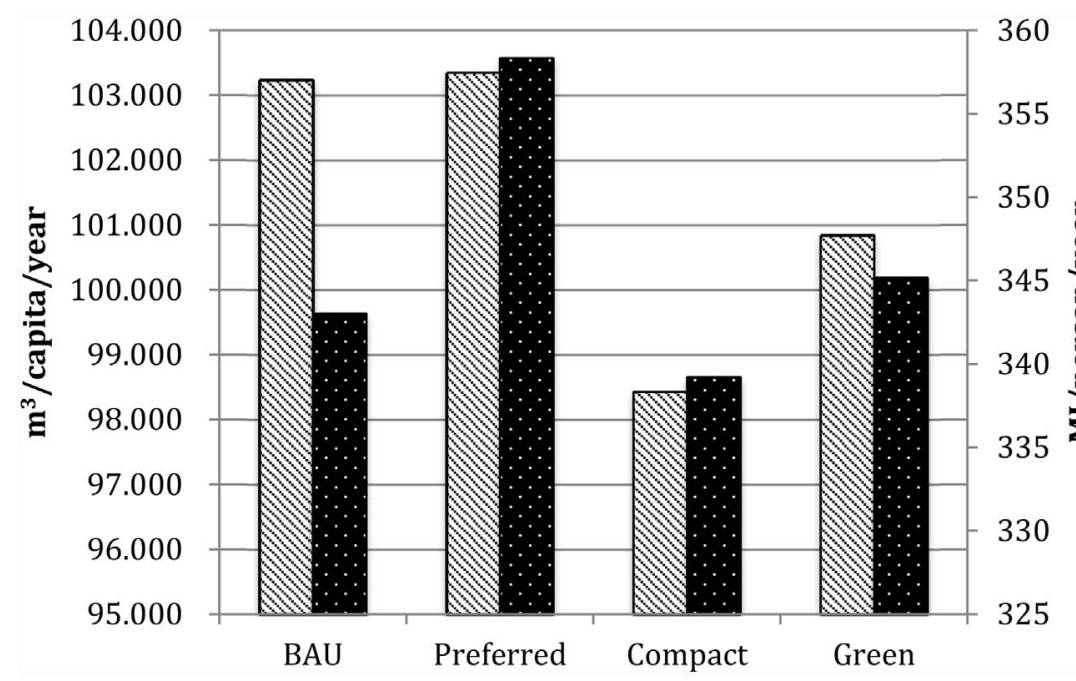

Fig. 5. Per capita water use (stripes) and operational energy (dots) by Tampa Water Service Area future development scenariosj.

Table 4

Breakdown of the total water consumption associated with each of the four development scenarios.

\begin{tabular}{|c|c|c|c|c|}
\hline & $\begin{array}{l}\text { Business as } \\
\text { Usual }\end{array}$ & Preferred & Compact & Green \\
\hline $\begin{array}{l}\text { Base Demand }\left(\mathrm{m}^{3} /\right. \\
\text { year) }\end{array}$ & $55,536,026$ & $55,536,026$ & $55,536,026$ & $55,536,026$ \\
\hline $\begin{array}{c}\text { New Employment } \\
\left(\mathrm{m}^{3} / \text { year }\right)\end{array}$ & $4,584,293$ & $12,215,904$ & $12,030,518$ & $9,932,099$ \\
\hline $\begin{array}{c}\text { New Single Family } \\
\left(\mathrm{m}^{3} / \text { year }\right)\end{array}$ & $11,503,287$ & $20,792,811$ & $9,097,908$ & $13,442,962$ \\
\hline $\begin{array}{l}\text { New Multi-Family } \\
\left(\mathrm{m}^{3} / \text { year }\right)\end{array}$ & $5,005,380$ & $25,868,104$ & $32,810,104$ & $22,862,566$ \\
\hline $\begin{array}{c}\text { New Townhomes } \\
\left(\mathrm{m}^{3} / \text { year }\right)\end{array}$ & 76,078 & $2,473,386$ & $1,763,136$ & $2,044,757$ \\
\hline Total Population & 742,900 & $1,131,091$ & $1,129,866$ & $1,029,542$ \\
\hline $\begin{array}{l}\text { Total Water } \\
\text { Consumption } \\
\left(\mathrm{m}^{3} / \text { year }\right)\end{array}$ & $76,705,064$ & $116,886,231$ & $111,237,692$ & $103,818,410$ \\
\hline
\end{tabular}

water consumption due to employment. The new employment demand of the BAU scenario ( 4.6 million $\mathrm{m}^{3}$ /year) is only a little over $1 / 3$ of total demand from new employment associated with the Preferred scenario (12.2 million $\mathrm{m}^{3}$ /year) as shown in Table 4. Because the new employment demand is also normalized by the total population, it is responsible for the higher per-capita water demand associated with the Preferred scenario, and to a degree, with the lower relative decreases in per-capita water usage of the Compact and Green scenarios, compared to the BAU scenario. Smart growth scenarios project the concentration of more development in existing urban areas, hence the addition of more jobs within the Tampa WSA. By excluding new employment consumption (which ranges from 6 to $11 \%$ of total water consumption), the Preferred, Compact, and Green scenario per-capita water use values are $5 \%, 10 \%$, and $6 \%$ lower than the BAU scenario, respectively.

The BAU scenario also has the second lowest per-capita water supply energy use (343 MJ/person/year). In this context, the relatively low operational energy value associated with the BAU scenario $\left(3.32 \mathrm{MJ} / \mathrm{m}^{3}\right.$ ) compensates for the higher per-capita water use value, thus resulting in a lower per-capita water supply energy use for the BAU scenario than that of the Preferred and Green scenarios. Only the Compact scenario is lower by a percentage of about $1.1 \%$. However, by excluding new employment water consumption, the BAU scenario maintains a higher per-capita water supply energy usage compared to the Preferred, Compact, and Green scenarios, which are associated with decreases of $0.5 \%, 6.2 \%$, and $3.2 \%$, respectively.

\section{Discussion}

Generally, the operational energy of water distribution is a significant contributor to the total operational energy of a potable water supply system (Amores et al., 2013; Lundie et al., 2006). Santana et al. (2014) estimated the energy used exclusively for water treatment is about $3.32 \mathrm{MJ} / \mathrm{m}^{3}$ (assuming only $15 \%$ of the total pumping energy is used during the treatment process) (EPRI, 2000). As a result, distribution in this study is responsible for about $50 \%$ of total potable water embodied energy in the city of Tampa. This is similar to the energy contributions of the distribution stage of potable water systems in past studies, which range from 55\% to 70\% (Amores et al., 2013; Lundie et al., 2006). Possible explanations for differences in contribution are treatment processes (desalination has been estimated to consume at least 10 times the amount of energy as conventional treatment systems), total distribution system pipe length, pipe age and conditions, and topography (Tampa is generally flat while Tarragona, Spain has a more varied topography) (Amores et al., 2013; Del Borghi et al., 2013).

With respect to potable water provision in the City of Tampa Water Service Area, smart growth principles related to urban layout were found to only make a small difference in terms of water distribution operational energy. While the BAU scenario projects more single-family home development at the northern and eastern margins of the city, the increased household water consumption in these areas results in a slightly lower operational energy intensity (which is based on a per unit volume of water used) than the smart growth scenarios, which estimate more growth in the southern and western parts of the Tampa WSA. More energy is needed to transport water to the northern, southern, and western regions of the WSA, which are farther from the treatment plant. Therefore, the operational energy value is sensitive to significant increases in development in these regions of the Tampa WSA. As a result, in terms of water distribution and the operational energy of water, distance from the treatment plant plays a more important role than the implementation of smart growth.

Only one previous study has compared the embodied energies of theoretical water distribution systems of distinct urban forms (Filion, 2008). Each theoretical urban form scenario had an operational energy (due to pumping) of about $466 \mathrm{MJ} /$ person/year (assuming an energy density of $3.48 \mathrm{MJ}$ used/MJ produced). The total water consumption in each scenario was also the same, while differences were in the layout of the water distribution systems and the population densities at the consumption nodes (which drove water consumption). In contrast, each development scenario in this study relies on the same distribution system layout, while the areas of increased water consumption were varied based on projected future water consumption patterns, resulting 
in different amounts of the total water use within the Tampa WSA.

With respect to water use, the Compact scenario modeled by One Bay shows a relatively lower per-capita water use and water supply energy use than the BAU scenario. This is primarily because of differences in composition of housing types and the amount of jobs added in each scenario. While the Compact scenario has a smaller percentage of single-family homes than the BAU scenario, the higher number of jobs added to the Compact scenario moderates much of this per capita water use decrease from the BAU to the Compact scenarios. As a result, the Compact scenario projects a $5 \%$ decrease in per-capita water use, and a $1.1 \%$ decrease in per-capita water supply energy use relative to the BAU scenario. By exclusively focusing on residential water use for the Tampa WSA, the more smart-growth-oriented planning paradigms (Preferred, Compact and Green) show decreases in per-capita water and water supply energy use, relative to the BAU scenario, of up to about $10 \%$, and $6.2 \%$, respectively. Therefore, the second principle of smart growth, "take advantage of compact building design" and the third principle, "create a range of housing opportunities and choices" (see Table 1), must be aggressively implemented to residential water use to offset additional water use due to employment in order to minimize overall per-capita residential water and water supply energy use. Taking this into account, if the future population is the same for each scenario $(742,900$ people), the Compact scenario would yield a net residential water supply energy savings of $2.8 \mathrm{TJ} /$ year. This is equivalent to the average yearly energy consumption of about 60 households in Florida (Energy Information Administration, 2015).

While potable water distribution is energy intensive and, in many conventionally based water treatment and supply systems, the highest energy contributor, when integrating the energy associated with indoor water use, this operational energy is significantly lower. According to a report by the Energy Information Administration (EIA), the average household in Florida dedicates about 8.1 million BTU (8500 MJ) annually to heating water for uses that include showering, dishwashing, and washing clothes (Energy Information Administration, 2013). Normalized by an average total household water use of about 199 GPUD (753 LPUD), the operational energy associated with water heating is approximately $108 \mathrm{MJ} / \mathrm{m}^{3}$ of total water used (heated and unheated). By integrating the results from this study and Santana et al. (2014), distribution and treatment together account for only $6 \%$ of the total embodied energy of residential water provision when including indoor water related energy use. Therefore, any improvement in the operational energy of potable water distribution will have only a minimal effect on the total embodied energy of potable water.

In order to reduce water-associated energy use, smart growth planning principles must including the objective of minimizing water usage. Less water usage requires less treatment, distribution, and heating of water, thus resulting in an overall decrease in energy usage. With respect to residential water use, smart growth, via compact design, has the potential to result in water savings, and consequently, energy savings. On average, smaller housing units use less water than larger housing units. Compared to the BAU scenarios, residential water energy consumption in smart growth scenarios is about $6.2 \%$ less. This comparison is also supported by another study by Runfola et al. (2013) in which water use is projected to increase $2.2 \%$ in a smart growth scenario compared to the $7.7 \%$ growth associated with a "current" growth scenario. Application of the smart growth principle of "distinctive, attractive communities" via the integration of native landscapes (or xeriscaping) can aid in minimizing water use as native flora may not need as much water. Planning that aesthetically integrates existing urban water infrastructure into community green space may be an alternative to lawns, thus minimizing outdoor water use (Wright Wendel, Downs, \& Mihelcic, 2011). In addition, a decrease in lawn size or lawns overall can translate into the avoidance of fertilizers, which are currently responsible for loadings reaching $2024 \mathrm{t} /$ year (1840 t) in the Tampa Bay watershed alone (Tampa Bay Estuary Program, 2008) and are large contributors to anthropogenic eutrophication in urban environments (UNEP \& WHRC, 2007). Meanwhile, incentivizing more efficient water heating technologies via efficiency standards or promotion of solar water heating systems can aid in decreasing the energy used to heat water (Hernandez \& Kenny, 2012; Koomey, Dunham, \& Lutz, 1995).

According to this study, smart growth may improve the city but does not necessarily improve the operational energy of the water supply. One main issue is that this study focused on the city, while the materials provided by OneBay analyze growth projections for the entire, Tampa-Clearwater-St.Petersburg metropolitan area. Therefore, future studies on the operational or the embodied energy of water management systems should focus on the entire metropolitan area. All future development scenarios result in the same projected number of inhabitants, yet growth is focused in different areas, which rely on different water treatment and supply characteristics. Smart growth scenarios concentrate growth and development in existing urban areas, while the Business as Usual scenario focuses growth outside of cities. As a result, future embodied energy calculations would be dependent on the different water treatment and supply systems of the areas where development would be projected to occur (Bonton, Bouchard, Barbeau, \& Jedrzejak, 2012; Filion, 2008).

A decrease in energy use automatically assumes a decrease in greenhouse gas emissions, thus aiding in the further prevention of human-induced climate change. Currently, rising sea levels have increased the frequency of flooding events in South Florida (Kolbert, 2016). Projections for Florida augur a 1-m sea level rise by 2100, with the southern and downtown portions of the city of Tampa as the most vulnerable to flooding (Florida Oceans and Coastal Council, 2010; Mooney, 2015). This represents a conflict as the smart growth scenarios concentrate more growth in downtown Tampa. Highlighting the consideration that, future growth plans will also have to take into account vulnerable areas such as waterfront communities. For instance, continued development in vulnerable areas such as downtown may mean the placement of pumps for water drainage to mitigate flooding events, resulting in even more energy usage. One vulnerable community in South Florida proposed the relatively drastic solution of encouraging depopulation (Kolbert, 2016). In summary, future studies and growth scenarios could incorporate climate change predictions and flooding maps to determine optimum areas for increased development that are associated with the least energy use and located in the least vulnerable areas.

It is important to note that cities vary in layout, organization, and topography. Therefore, the results of this study are limited in applicability to other cities. For instance, Tampa is sprawled city located on relatively flat land. Meanwhile, Pittsburgh is hilly and with a higher population density. Also Tampa's water source is located in the middle of the city. For many cities in the United States, this is not the case. New York City's water source is located about 125 miles from the city itself. As a result, the procedure carried out in this study can help municipalities determine the effects of their future smart growth planning initiatives on the embodied energy of water supply.

\section{Conclusions}

Smart growth has been shown to result in vibrant communities, lower greenhouse gas and conventional air pollutant emissions, and possibly less water use (Guhathakurta \& Gober, 2007; Harrison et al., 2012; Lee \& Lee, 2014; Nahlik \& Chester, 2014; Runfola et al., 2013). However, in terms of water distribution energy use, the overall hypothesis that guided our research was rejected because smart growth was found to have a minimal effect on the energy associated with water treatment and supply. In part, this was due to the predominance of urban growth outside of the city of Tampa WSA in the Business as Usual scenario, resulting in less additional households than the smart growth scenarios. Also, the spatial allocation of additional demand from the 
water treatment facility location was found to play a prominent role in determining the operational energy. Nevertheless, smart growth was found to result in possible water savings, as demonstrated by lower percapita water consumption and water supply energy use (Compact scenario) in development scenarios that tend toward smart growth due to housing composition. Water treatment was found to have a similar embodied energy to water distribution in this study. Therefore, any significant savings in water use at the household level has a direct impact on energy savings and associated pollutant emissions. Therefore, the second principle of smart growth, "take advantage of compact building design" can result in a decrease in water-associated energy use, which can be even greater when taking into account the energy avoided by heating less water. Finally, the results of this study show how future development scenarios that simulate different growth alternatives for a certain region can be used to determine their environmental impacts with respect to water management. As cities develop future development plans (many including smart growth), the methodology used here can aid in determining projections of energy and environmental impacts.

\section{Acknowledgments}

This material is based upon work supported by the National Science Foundation Partnerships for International Research and Education (PIRE) Grant under Grant No. 1243510. Additional support for this research was provided by the Department of Education Graduate Assistance in Areas of National Need Fellowship, the Alfred P. Sloan Minority PhD Fellowship, and the McKnight Doctoral Dissertation Fellowship. Special thanks is also given to Brady Smith from the Tampa Bay Regional Planning Council, Seung Park from the City of Tampa Water Department, and David Bracciano from Tampa Bay Water.

\section{References}

Amores, M. J., Meneses, M., Pasqualino, J., Anton, A., \& Castells, F. (2013). Environmental assessment of urban water cycle on Mediterranean conditions by LCA approach. Journal of Cleaner Production, 43, 84-92. http://dx.doi.org/10.1016/j. jclepro.2012.12.033.

Behan, K., Maoh, H., \& Kanaroglou, P. (2008). Smart growth strategies, transportation and urban sprawl: simulated futures for Hamilton, Ontario. Canadian Geographer 52(3), 291-308. http://dx.doi.org/10.1111/j.1541-0064.2008.00214.x.

Bonton, A., Bouchard, C., Barbeau, B., \& Jedrzejak, S. P. (2012). Comparative life cycle assessment of water treatment plants. Desalination, 284(0), 42-54. http://dx.doi.org/ 10.1016/j.desal.2011.08.035.

Cornejo, P. K., Santana, M. V. E., Hokanson, D. R., Mihelcic, J. R., \& Zhang, Q. (2014) Estimating greenhouse gas emissions for water reuse and desalination facilities. Journal of Water Reuse and Desalination, 4(4), 238-252.

Del Borghi, A., Strazza, C., Gallo, M., Messineo, S., \& Naso, M. (2013). Water supply and sustainability: Life cycle assessment of water collection, treatment and distribution service. The International Journal of Life Cycle Assessment, 18(5), 1158-1168. http:// dx.doi.org/10.1007/s11367-013-0549-5.

EPRI (2000). U.S. electricity consumption for water supply and treatment - The next half century. Palo Alto, CA: EPRI.

Energy Information Administration (2013). Household site end-use consumption in the south region, totals and averages, 2009. In CE3.4 Site End-Use Consumption in South.xlsx (Ed.), Washington, D.C: EIA.

Energy Information Administration (2015). 2013 - average monthly bill - residential. In Table 5_a.xls (Ed.),

Environmental Protection Agency (2008). EPANET. Retrieved April 22, 2017 from https://www.epa.gov/water-research/epanet.

Environmental Protection Agency (2016). Water use today. Retrieved December 10, 2016 from https://www3.epa.gov/watersense/our_water/water_use_today.html.

Filion, Y. R. (2008). Impact of urban form on energy use in water distribution systems. Journal of Infrastructure Systems, 14(4), 337-346. http://dx.doi.org/10.1061/(asce) 1076-0342(2008)14:4(337).

Florida Center for Community Design and Research (2015). Hillsborough community atlas. Retrieved April 2, 2015 from http://www.hillsborough.communityatlas.usf.edu.

Florida Oceans and Coastal Council, (2010). Climate change and sea-level rise in Florida: An update of The effect of climate change on Florida's ocean and coastal resources,
Tallahassee, FL.

Guhathakurta, S., \& Gober, P. (2007). The impact of the Phoenix urban heat island on residential water use. Journal of the American Planning Association, 73(3), 317-329. http://dx.doi.org/10.1080/01944360708977980.

Hankey, S., \& Marshall, J. D. (2010). Impacts of urban form on future US passengervehicle greenhouse gas emissions. Energy Policy, 38(9), 4880-4887. http://dx.doi. org/10.1016/j.enpol.2009.07.005.

Harrison, M., Stanwyck, E., Beckingham, B., Starry, O., Hanlon, B., \& Newcomer, J. (2012). Smart growth and the septic tank: wastewater treatment and growth management in the Baltimore region. Land Use Policy, 29(3), 483-492. http://dx.doi. org/10.1016/j.landusepol.2011.08.007.

Hazen, Sawyer, (2013). 2013 Tampa Bay Water management plan, Clearwater, FL.

Hernandez, P., \& Kenny, P. (2012). Net energy analysis of domestic solar water heating installations in operation. Renewable and Sustainable Energy Reviews, 16(1), 170-177. http://dx.doi.org/10.1016/j.rser.2011.07.144.

Hillsborough County Metropolitan Planning Organization (2009). Hillsborough County 2035 long range transportation plan. Tampa, FL: Hillsborough County Metropolitan Planning Organization.

Kolbert, E. (2016). The siege of Miami. New Yorker. Retrieved from http://www newyorker.com/magazine/2015/12/21/the-siege-of-miami.

Koomey, J. G., Dunham, C., \& Lutz, J. D. (1995). The effect of efficiency standards on water use and water-heating energy use in the US: A detailed end-use treatment. Energy, 20(7), 627-635. http://dx.doi.org/10.1016/0360-5442(95)00005-2.

Lee, S., \& Lee, B. (2014). The influence of urban form on GHG emissions in the U.S. household sector. Energy Policy, 68, 534-549. http://dx.doi.org/10.1016/j.enpol. 2014.01.024.

Lundie, S., Peters, G. M., \& Beavis, P. C. (2004). Life cycle assessment for sustainable metropolitan water systems planning. Environmental Science and Technology, 38(13), 3465-3473.

Mo, W., Zhang, Q., Mihelcic, J. R., \& Hokanson, D. R. (2011). Embodied energy comparison of surface water and groundwater supply options. Water Research, 45(17), 5577-5586.

Mooney, C. (2015). This is how rising sea levels will reshape the face of the Tampa Bay area. Tampa Bay Times. Retrieved from http://www.tampabay.com/news/environment/ water/this-is-how-rising-sea-levels-will-reshape-the-face-of-the-tampa-bay-area/ 2249781.

Nahlik, M. J., \& Chester, M. V. (2014). Transit-oriented smart growth can reduce lifecycle environmental impacts and household costs in Los Angeles. Transport Policy, 35, 21-30. http://dx.doi.org/10.1016/j.tranpol.2014.05.004.

Nelson, A. C. (2004). Planner's estimating guide: Projecting land use and facility needs Chicago. Planners Press.

Pelley, J. (2004). Perspective: Is smart growth better for water quality? Environmental Science \& Technology, 38(19), 365A-366A. http://dx.doi.org/10.1021/es040635o.

Runfola, D. M., Polsky, C., Nicolson, C., Giner, N. M., Pontius, R. G., Krahe, J., et al. (2013). A growing concern? Examining the influence of lawn size on residential water use in suburban Boston, MA, USA. Landscape and Urban Planning, 119, 113-123. http://dx.doi.org/10.1016/j.landurbplan.2013.07.006.

Santana, M. V. E., Zhang, Q., \& Mihelcic, J. R. (2014). Influence of water quality on the embodied energy of drinking water treatment. Environmental Science \& Technology, $48(5)$

Smart Growth Network (2006). This is smart growth. Retrieved from http://www.epa.gov/ smartgrowth/pdf/2009_11_tisg.pdf.

Stokes, J., \& Horvath, A. (2011). Life cycle assessment of urban water provision: Tool and case study in California. Journal of Infrastructure Systems, 2011(17).

Tampa Bay Estuary Program (2008). Technical memorandum: Model-based estimates of nitrogen load reductions associated with fertilizer restriction implementation. St. Petersburg: Tampa Bay Estuary Program.

U.S. Census Bureau (2013). 2013 American housing survey for the Tampa-Clearwater-St Petersburg metropolitan area. In U. S. Census Bureau (Ed.), Washington, D.C: U.S Census Bureau.

UN-Habitat (2013). State of the world's cities 2012/2013: Prosperity of cities.

UNEP, \& WHRC (2007). Reactive nitrogen in the environment: Too much or too little of a good thing. Paris: United Nations Environment Programme.

United Nations Environment Programme (UNEP) (2011). Towards a green economy: Pathways to sustainable development and poverty eradication. Retrieved from www. unep.org/greeneconomy.

United Nations (2010). Trends in sustainable development: Towards sustainable consumption and production. New York: United Nations.

Walton, B. (2016). Infographic: Average U.S. household water use and bills, 2015-2016. Water News. [Retrieved from]. http://www.circleofblue.org/2016/watermanagement/pricing/infographic-average-u-s-household-water-use-bills-2015-16/.

Wright Wendel, H. E., Downs, J. A., \& Mihelcic, J. R. (2011). Assessing equitable access to urban green space: The role of engineered water infrastructure. Environmental Science \& Technology, 45(16), 6728-6734.

Xiang, W., \& Clarke, K. C. (2003). The use of scenarios in land use planning. Environment and Planning B: Planning and Design, 30(6), 885-909.

Yeh, C.-T., \& Huang, S.-L. (2012). Global urbanization and demand for natural resources. In R. Lal, \& B. Augustin (Eds.), Carbon sequestration in urban ecosystems. Columbus $\mathrm{OH}$ : Springer.

Yonkin, M., Clubine, K., \& O'Connor, K. (2008). Importance of energy efficiency to the water and wastewater sector. Clearwaters, 38, 12-13. 